\title{
A gentler structure to life: co-creation in branding a cultural route
}

\author{
Arja Lemmetyinen $^{1}\left[\right.$ [ Lenita Nieminen $^{1} \cdot$ Johanna Aalto $^{2}$
}

Revised: 10 May 2021 / Accepted: 12 May 2021 / Published online: 22 May 2021

(c) The Author(s) 2021

\begin{abstract}
The study explores how a cultural route supports the identity of a place. The study applies co-creative and identity-based place-branding theory and advances research on the significant role of culture when various actors identify with the brand of a place. Moreover, cultural sustainability is seen as a form of meta-narrative that frames the symbiosis of a place brand and its cultural values. Contributing to the previous research on branding a cultural route, this study discusses the value of a person (an architect) to the branding of a cultural route. The study also contributes to place-branding theory by linking the discourse on architectural heritage and branding an emerging cultural route. We used a single and critical case approach focusing on one of the sites representing a group of cities involved in the branding of the Alvar Aalto cultural route. Various qualitative research methods including interviews and publicly available material were utilized. The study presents empirical findings on branding an emergent cultural route. As a key theoretical contribution, the study shows how the culture and image of an individual site are expressed in the cohesive brand identity of that cultural route. Communication and co-creation are revealed to be prerequisites of efficient collaboration.
\end{abstract}

Keywords Architecture $\cdot$ Cultural route $\cdot$ Cultural sustainability $\cdot$ Heritage $\cdot$ Place branding $\cdot$ Value co-creation

\section{Introduction}

This study contributes to the discussion on place-branding theories evolving toward the brand-identity-based approach that addresses the culture of the place as part of its identity and integral to its image (Kavaratzis and Hatch 2013). Moreover, the study follows "recent paradigmatic shifts from managerial to co-creative branding and from consumer to multi-stakeholder approaches in marketing" (Von Wallpach et al. 2017, p. 395; see also Martinez 2016; Fan 2014). Previous studies have focused on the co-creation of a city's brand (Hatch and Schultz 2010; Merrilees et al. 2014; Casais and Monteiro 2019), while this study examines how a cultural

Arja Lemmetyinen

arinle@utu.fi

Lenita Nieminen

lenita.nieminen@utu.fi

Johanna Aalto

johanna.aalto@laurea.fi

1 University of Turku, Turku School of Economics, Pori Unit, Finland

2 Laurea University of Applied Sciences, Vantaa, Finland route exploits co-creation by several small localities to support a joint brand identity.

Thematic and cultural routes are attached to attractions organically tied to the geographical space. Furthermore, the uniqueness and individuality of a site are made distinct by integrating both physical and immaterial heritage into a thematic cultural route, thus offering a new space for discovery and experience seeking (Majdoub 2010). Linking attractions and activities in marginal or rural areas can then be used as a development tool for rural areas or small places not only by bringing visitors to the destination but also by stimulating cooperation and communication between local, regional, and national, and even international, communities. According to Mitoula and Kaldis (2019, p. 118), the cities connected to a cultural route tend to "develop their own identity and brand name so that visitors and general public opinion could associate the city with its cultural heritage, and also to develop its recognizable brand name with an emphasis on culture." Contrary to the previous approach which emphasizes the specific brand identity of each city along a cultural route, this study shows that all cities or places on a cultural route can benefit from operating under the same brand. The view is supported by Majdoub (2010), who claims that the search 
for common coherence is important when considering the image and visibility of a destination.

The purpose of this study is to explore how a cultural route expresses the identity of a place. Both academics and practitioners have become interested in the relationship between culture and place branding and understand that the culture of a place plays a significant role when residents and other stakeholders identify with the place's brand (Scaramanga 2015). This article follows prior research establishing cultural explanations of the place-branding process through which place brands are created (Pedeliento and Kavaratzis 2019; Mayes 2008). More specifically, the article examines the connectivity between architecture and place branding (Cvitković and Kline 2017). Owing to the unique attributes of individuals, place branding often uses personalities, such as artists with a local connection (architects, sculptors, or painters), to create associations with the place (Scaramanga 2015). We extend the previous stream of place-brand research by treating cultural sustainability as a kind of metanarrative that frames the symbiosis of a place brand and cultural heritage sites. By doing so we refer to the global challenge of "finding sustainable strategies for cities of all sizes," and enhancing understanding of "the changing relationship between urban and rural areas" (Soini and Dessein 2015, p. xvii). Placing cultural sustainability at the core of urban (and rural) development, the study explores "different models of local sustainability that incorporate emotions and attachment to one's living place" (ibid). Majdoub (2010) also considers cooperation important not only for the sustainability of rural tourism but also for the sustainable social and economic development of a local community.

The case of the Alvar Aalto route offers us an option to analyze the defining elements of a cultural route. The following sections present the theoretical background of the research and then describe the methodology alongside the data collection and analysis and key findings. The theoretical and practical implications are presented in the conclusions section alongside propositions for further research.

\section{Theoretical framework}

This study adopts a co-creative branding approach and thus follows "recent paradigmatic shifts from managerial to cocreative branding and from consumer to multi-stakeholder approaches in marketing" according to which "brand identity continuously emerges as a dynamic outcome of social processes of stakeholder interaction" (Wallpach et al. 2017, p. 395). This study accords with the interpretation grounded on the relationship between the place brand and place identity and with the suggestion of Kavaratzis and Hatch (2013, p. 69) that, "the true nature of place branding is revealed as one of interaction and dialogue between stakeholders." The conceptualization of Kavaratzis and Hatch (2013) emphasizes the ongoing dialogue between all the stakeholders in the brand-building process. In other words, place branding is seen as a tool that permits the locals to communicate the cultural features of the place, or in our case, the sites along a cultural route. There is a need for internal communication between the actors when creating the core of a correct and clear place-brand image (Moilanen and Rainisto 2009). According to Aaker (2014), the enthusiasm for the place brand is also a considerable advantage when implementing a joint strategy —in our case for the cultural route. Communication also consists of the customer side and then the most suitable situation is that the communication is a two-way process (Vargo and Lusch 2008; Warnaby 2009).

This study illustrates that branding a cultural route can be seen from the viewpoint of finding sustainable development strategies for cities of all sizes (Auclair and Fairclough 2015). Auclair and Fairclough (2015) claim that while there is ample research on cities and sustainability only a few studies place cultural sustainability at the core of urban and rural development. Tourist routes are based on networking and local collaboration which, in turn, may stimulate the adoption of sustainable practices as a wide range of tourism stakeholders should be included. Mitoula and Kaldis (2019) see the role of city branding as being to strengthen the sustainable development of the city and surrounding area by highlighting and exploiting the features of local cultural heritage. The same study defines cultural routes as a basic management tool for the empowerment of cultural tourism and notes that such events may be structured tours around a central thematic axis seeking to highlight the relevant historical and natural, intangible, and material monuments of a city or a larger area (ibid). The international scientific committee on cultural routes (ICOMOS) states a cultural route has "its own specific dynamic and historic functionality, which must fulfill the following conditions: It must arise from and reflect interactive movements of people as well as multi-dimensional, continuous, and reciprocal exchanges of goods, ideas, knowledge, and values between peoples, countries, regions or continents over significant periods of time" (Majdoub 2010, p. 30).

Richards (2011) noted that cultural routes play an important role in cultural tourism not only because of the physical journey they offer but also because they tell stories about the sites situated along the route. Richards calls for a new landscape of cultural tourism to reflect a "shift from static museums and monuments more toward the creative cocreation of experiences, narratives and dreams." (Richards, 2011, p. xx.) Richards (2011) also notes that cultural routes can enable co-creation and collaboration between suppliers and enhance links between suppliers and consumers, and also increase contact with the local culture, the emphasis on everyday intangible heritage, and provide new grounds for 
authenticity (a move away from authority toward context and originality). Much recent research has traced the concept of cultural heritage as it extends from a focus on the tangible to incorporate intangible heritage (Richards 2018). Moreover, the concept of cultural heritage has broadened to incorporate intangible goods that reflect the recognition of identity or to convey the value of tradition (Del Barrio et al. 2012). The increasing inclusion of tangible and intangible aspects of heritage in the tourism system is, however, prompting concerns about the sustainability of heritage (Richards 2018). A crucial question is whether the place-branding process can be guided through top-down planning initiatives, or if it is best stimulated through grass-roots, endogenous processes (Braun et al. 2013). As Richards (2020) notes, co-creative place-branding strategies need to be sensitive to local context and must be driven by a clear vision that encourages co-creation among the suppliers and developing a coherent narrative (Richards 2020).

Both Richards (2020) and Della Lucia and Trunfio (2018) view iconic architecture as among the most important cultural catalysts used to restore the identity of a place and attract visitors and tourists. Dovey (2014, pp. 158-159) emphasizes the role of an iconic architecture that is so fundamental that, "cities without icons are like corporations without logos." In line with Cvitković and Kline (2017), we focus on the connectivity between architecture and place branding. Similarly, Muratowski (2012) emphasizes the role of architecture in branding a city and argues that cities need a distinctive form of branding that promotes social relationships and individual enterprises, and also states that architecture can be used as "a symbol of a territorial identity" (p. 4). Parkerson and Saunders again (2005, p. 247) view the most important differentiating elements for branding a city/place as being "the sociocultural and the manmade." This view coincides with the classic brand equity concept consisting of the awareness of the brand, the associations attached to it, and the quality and loyalty linked to it (Aaker and Joachimstahler 2000).

Architecture can promote cultural values that reflect the heterogeneity of places (Muratowksi 2012, p. 7). The same article concludes with a key message: "city branding should be seen as a process that enhances the status of the city and the lives of its inhabitants by taking into account social, cultural, political and economic environments and practices" (Muratowksi 2012, p. 12). Asworth (2010), in turn, suggests it is logical to assume that as people are unique then places will acquire uniqueness through the association with a nominated person; in our study, that person is the architect Alvar Aalto. According to Halonen-Knight and Hurmerinta (2010, p. 457), "celebrity endorsement could become a more strategic alliance built around the linking and integration of the attributes of the two allying brands aiming to leverage the brand associations of the brands involved and enhance both brands' image and reputation." This is what the branders of the Alvar Aalto cultural route are aiming for when strengthening the brand associations between the route and the architect Alvar Aalto. Lewis (2010) examines the role and status of ordinary experts, such as Martha Stewart and Jamie Oliver, as examples of what is referred to as celebritization, and also characterizes these people and their branding as a living brand whose lifestyle expertise has become thoroughly commodified and merchandized (Lury 2004; Lewis 2010).

The theoretical discussion above is synthesized in the conceptualization of Kavaratzis and Hatch (2013) that presents place branding as a co-creative dialogue between stakeholders. As illustrated in Fig. 1, place branding leaves impressions on others and the changes in the image of the place as well as the culture of the place will be mirrored in the brand identity. This study applies that model of Kavaratzis and Hatch (2013) in the context of branding a cultural route and views the identity of the place as the identity of the cultural route.

Prior studies (The Authors 2021) suggest interactive communication between the stakeholders of a local cultural community is one of the prerequisites for effective co-creation. Consequently, in Fig. 1 communication and co-creation are shown as dimensions of networked cooperation between the sites of a cultural route. Following Majdoub (2010, p. 30), the elements of a cultural route have been included in Fig. 1 . They are context, content, cross-cultural significance, and the character of a route. Context refers to the natural setting; content to tangible and physical elements of cultural heritage; and cross-cultural significance implies a value as a whole that then gives a route its character-the core of the brand identity. In the analysis of the empirical data, we use the 6Cs of Branding a Cultural Route framework.

\section{Methodology and data analysis}

This study explores how a cultural route supports the identity of a place by illustrating how the elements of a cultural route become apparent. Our study can be characterized as "an intensive examination of a single case, which forms the basis for a theoretical analysis" (Bell et al. 2019, p. 66). We have chosen to investigate one of the sites on the Alvar Aalto cultural route as we know the site well having studied it for a considerable period. We started gathering data and working with key persons connected to the Alvar Aalto cultural route before the route was officially established. At the time of the interviews, one of the authors of the current study held an administrative management role for the local municipality that involved planning the development projects for the area. The two other authors also attended many of the related events. Our long-term involvement with the site provided 


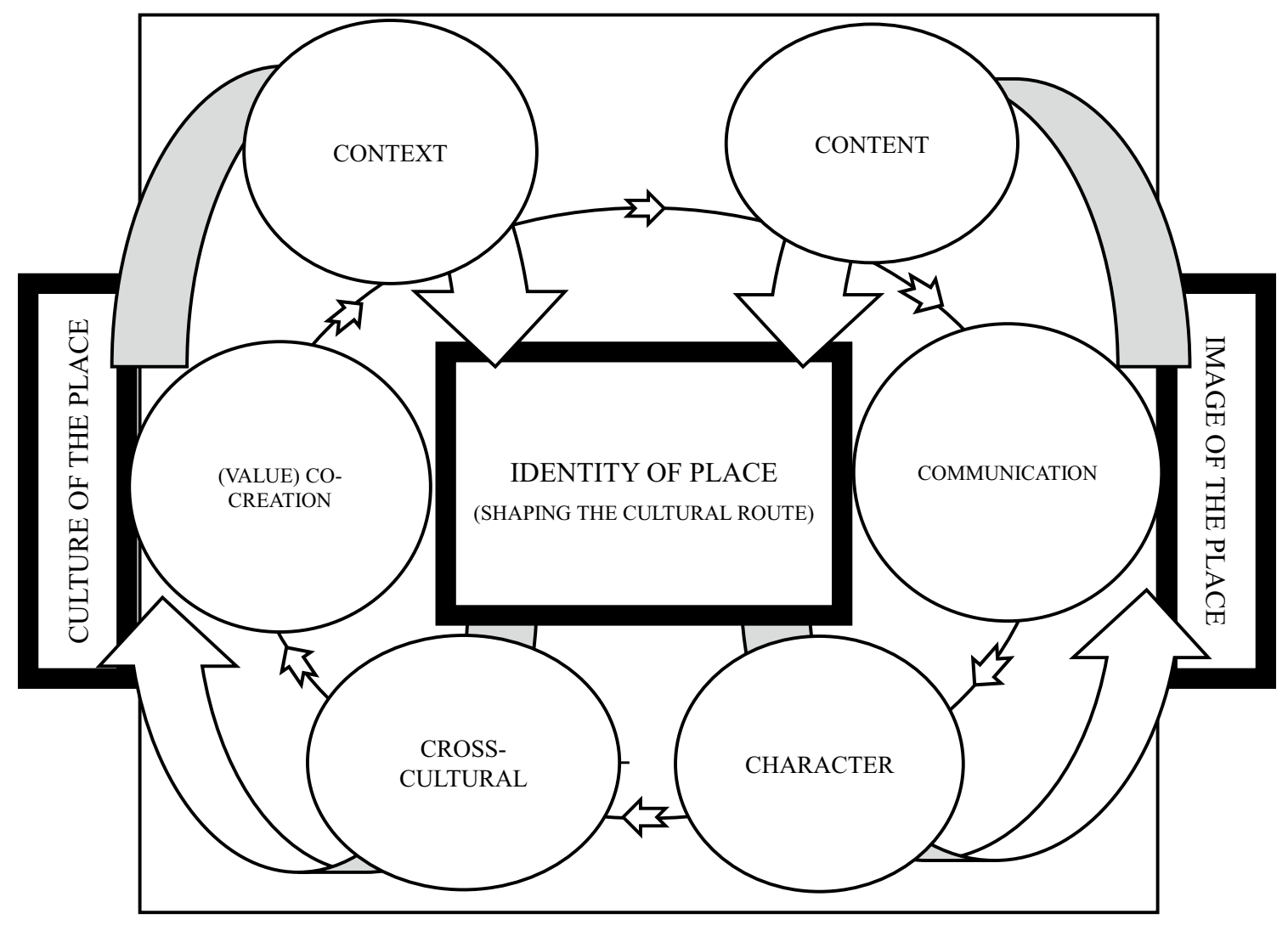

Fig. 1 The 6Cs of branding a cultural route (modified from Kavaratzis et al. 2013; Majdoub 2010; the Authors 2021)

easy access to data and meant we could observe and investigate a variety of activities supporting the emergence of the cultural route. Taking an ethnographic approach enabled the researchers to observe actors in the field (Merriam and Tisdell 2016) and follow developmental activities as they unfolded (Tedlock 2000).

The planning of a new Alvar Aalto cultural route started in 2017 as part of an aim to create an international brand (Alvar Aalto Foundation 2019a). Alvar Aalto (1898-1976) is one of Finland's most famous architects and designers, and it is estimated he designed around 500 buildings throughout his long career, which made his name a brand in the USA as early as the 1930s. As an architect, Aalto wanted to base his creativity on solid social and human values, and this was his way "to give life a gentler structure" (Holma and Lahti 1996). There are about 40 cities around the world associated with Alvar Aalto (Alvar Aalto Foundation 2019b). A private Alvar Aalto Foundation and a group of 21 cities in Finland hosting significant buildings designed by Alvar Aalto started a co-creative networking project to secure Alvar Aalto's material and intellectual inheritance and to promote awareness of his work. The goal is to apply for the designation of the Alvar Aalto route as a cultural route certified by the Council of Europe. The Alvar Aalto Foundation also plans to apply to have the sites of Aalto's work designated UNESCO world heritage sites (WHS). Earlier research on WHS has to a great extent been connected to the tourism specialization and economic development of the sites (Arezki, Cherif and Piotrowski 2009; Frey, Pamini and Steiner 2011; Kayahan and Vanblarcom 2012) or the impact of the designation on the local communities (Jimura 2011). Several studies and case examples show that the WHS designation spurs considerable growth in tourist flow and visitor awareness (King and Halpenny 2014) and local inhabitants react positively to the world heritage symbol (Jimura 2011).

We selected a case we assessed would provide the most constructive learning experience. Our case study is an instrumental case study, meaning we focus on learning about and understanding a broader issue through a detailed examination of one particular case (Stake 1995). The current research could also be described as a critical case study, which according to Yin (2003) offers a comprehensive understanding of the circumstances relevant to the analysis. Knights and McCabe (1997) argue that a case study offers a vehicle through which to unite several qualitative methods. The data supporting this study were gathered using various qualitative research methods including interviews and publicly available texts. The study started in 2012 when we gathered data from one of the sites on the Alvar Aalto cultural route. The particular site is widely 
known for its buildings designed by Alvar Aalto. The textual research material of the study comprised 10 items of news and notices published by the Alvar Aalto Foundation and other content on the publicly available official website of the Alvar Aalto Foundation (www.alvaraalto.fi) and the Alvar Aalto route (visit.alvaraalto.fi) published between 2017 and 2020 (Rapley and Rees 2018). The material was collected and organized before content analysis was undertaken (Patton 2002; Silverman 2013).

We conducted intensive face-to-face interviews (Riessman 2004) with five small business owners, a representative of the company that owned many of the Aalto buildings on the site, two representatives of NGOs operating in the local community, three municipality representatives who had a coordinating role in the brand-building of the place, and representatives from two public sector agencies.

In addition, in 2018, we interviewed the coordinator of the Alvar Aalto route from the Alvar Aalto Foundation by telephone to discern how the branding project of the Alvar Aalto cities had been developed and the intentions around marketing the route. We also held several conversations at various events with the interviewees. The interviewees' profiles are presented in Table 1.
We analyzed the data by conducting a thematic analysis, which is one of the most common approaches applied in qualitative data analysis (Bell et al. 2019). In searching for themes, we identified recurring topics among the accounts of the interviewees (Ryan and Bernard 2003; Bell et al. 2019). In our data, the name of the architect Alvar Aalto often came up when the interviewees were asked what aspects should be highlighted in the branding of the area. Clearly, Alvar Aalto's architecture was considered to hold significant value for the identity of the site. We identified similarities and differences in the narratives of the interviewees and also identified categories, which we presented as dimensions and elements of a cultural route following the theoretical framework of our study. Consequently, we used those categories as "a springboard for themes" in analyzing the data (Bell et al., 2019, p. 519). This action aligns with the work of Braun and Clarke (2006) emphasizing that the themes identified in a qualitative study not only relate to the research focus of the study but also provide a basis for the researchers' theoretical understanding of the data (Bell et al. 2019). The following section includes an analysis of the data categorized that encapsulated the elements and dimensions of a cultural route.

Table 1 Interviewees of the study

\begin{tabular}{|c|c|c|}
\hline Interviewees & Small business entrepreneurs & Interviewed \\
\hline 1 & Visual and performance artist who runs an art gallery and a perfume shop established in 1936 by her mother & 2014 \\
\hline 2 & $\begin{array}{l}\text { Owner of a design sauna who runs a cafeteria in a building designed by architect Alvar Aalto in the 1940s then func- } \\
\text { tioning both as a sauna and a laundry for the workers in the neighboring factories }\end{array}$ & 2014 \\
\hline 3 & $\begin{array}{l}\text { Owner of an art house who started a cultural center on an old family estate to display her artwork and paintings, and } \\
\text { also to generate some income to cover the costs of the house }\end{array}$ & 2014 \\
\hline 4 & $\begin{array}{l}\text { Owner of a boutique offering quality fashion brands for women and men. The name of her shop incorporates the } \\
\text { first names of a couple of an old local industrial family }\end{array}$ & 2014 \\
\hline 5 & $\begin{array}{l}\text { Handicraft artisan who ran handicrafts and cultural tourism enterprises for more than } 20 \text { years but has now closed } \\
\text { her business. She still works as an artist and is active in the local artists association }\end{array}$ & 2020 \\
\hline \multirow[t]{2}{*}{6} & $\begin{array}{l}\text { Service director at the company that owns many of the historic buildings on the site. The firm started a new line of } \\
\text { business offering guest services in } 2010\end{array}$ & 2014 \\
\hline & NGOs & \\
\hline 7 & $\begin{array}{l}\text { Coordinator of the local non-profit youth association. In the Ironworks Village, also runs a summer café with a } \\
\text { sideline selling local handicrafts }\end{array}$ & 2014 \\
\hline \multirow[t]{2}{*}{8} & $\begin{array}{l}\text { Executive director of artist-in-residence program (an independent association) seeking to bring the art world and the } \\
\text { community closer together. Activities are funded by local and regional art and cultural institutions, organizations, } \\
\text { and individuals }\end{array}$ & 2020 \\
\hline & Municipal representatives & \\
\hline 9 & Administrative manager & 2014 \\
\hline 10 & Cultural manager & 2014 \\
\hline \multirow[t]{2}{*}{11} & Business development manager & 2014 \\
\hline & Other public sector agencies & \\
\hline 12 & $\begin{array}{l}\text { Executive director at the regional research center acting as a national specialist in the fields of bioeconomy, the food } \\
\text { industry, and water protection and as a member of international, interdisciplinary networks }\end{array}$ & 2014 \\
\hline 13 & $\begin{array}{l}\text { Executive director of the regional association that develops rural areas, e.g., living villages and rural tourism related } \\
\text { to nature, culture, art, and crafts. Activities are mainly funded by the EU }\end{array}$ & 2014 \\
\hline 14 & Representative of the Alvar Aalto Foundation & 2018 \\
\hline
\end{tabular}




\section{Key arguments/findings}

The content analysis of the textual materials started with the notice of application for the establishment of the Alvar Aalto cities network in February 2017. The productization of the joint route was agreed upon between the 21 target cities, which have made great efforts to promote sites associated with Alvar Aalto. The coordinator of the Alvar Aalto Foundation confirmed the intention was to increase the visibility and awareness of all Aalto sites by organizing a collaborative network and a joint brand and to launch a website capable of presenting the whole route. The textual analysis of the content primarily shows the legacy of Aalto's work derived from the cultural heritage of the place (Alvar Aalto Foundation 2019a; 2019b). The phases of the cooperation with the timeline and stages were clearly distinguished in the material, for example, the setting up of a Finnish Alvar Aalto route (February 2018) and the opening of a new web page built around Alvar Aalto's architecture in May 2018.

Internal communication has been key to the development of the route. The Alvar Aalto Foundation (2019b) coordinates cooperation (Interviewee 14, representative of the Alvar Aalto Foundation) in an egalitarian and nonhierarchical network (Interviewee 9, administrative manager) creating circumstances in which "brand identity continuously emerges as a dynamic outcome of social processes of stakeholder interaction" (Wallpach et al. 2017). Marketing the cultural Alvar Aalto cities as a cohesive cultural route will serve a new and varied audience with a special interest in architecture. Authorized travel agencies are now selling Alvar Aalto city tours.

The context of a cultural route refers to the natural setting of a route (Majdoub 2010). In the case of Alvar Aalto route the history and traditions of the preceding generations are safeguarded by ensuring that the business is profitable. In the interview material this can be perceived, e. g. the large family-run company - the owner of most of the buildings on the site with a strong cultural and industrial heritage - sees enormous value in maintaining, preserving, and developing the site. The service director envisages the place being full of life and not merely a museum. Alvar Aalto's architecture has attracted a combination of micro, small, and large enterprises to cooperate, even before the networking for the Alvar Aalto cities project started. Acting under a joint brand identity was one of the main goals of the local enterprises and those involved in business development before the network expanded to involve all the Alvar Aalto cities. The activity on the site resonates with the emphasis placed by Von Wallpach et al. (2017) on the recent paradigmatic shift from managerial to cocreative branding and from consumer to multi-stakeholder approaches in marketing that stress the relationship between the place brand and place identity (Kavaratzis and Hatch 2013).

We have this image of industrial history and you can still sense the life of work and industry here. You see the smoke of the factory chimneys and meet the many foreign employees of the factories. Many of them also live in the area. (Interviewee 6, service director)

Our data show that the buildings designed by Alvar Aalto are part of people's everyday lives, constituting part of the content of their lifestyles with roots in the history that influences their livelihood and housing in the village. The built environment has been an integral part of their childhood, youth and adulthood. Some of the interviewees also tell about the persons about the experiences of earlier generations. We emphasize the significant and often forgotten role of local inhabitants in co-creating a brand (Martinez 2016; Fan 2014).

Understanding the history of a place is the first step in creating something in common along the way to creating a brand for the village. If it did not have such a significant industrial history, the famous architect Alvar Aalto might never have come to the site. (Interviewee 9 , administrative manager)

The interviewees live and work in the village, which brings Aalto's architecture into their everyday lives; as illustrated in the following example:

I've been raised in this industrial environment, so I have probably grown into the Ironworks Village, and as I said, the sauna [designed by Alvar Aalto in the 1940s] was waiting for us to renovate it (Interviewee 2 , small business entrepreneur).

The international and cross-cultural significance of Aalto as crucial factor forming one site's strengths was evident in the interviews with the local stakeholders observed in the long-term case study. Those informants surmised that Aalto's design work in any of the Alvar Aalto cities would attract international architecture students and enthusiasts. Aalto's reputation is undeniable, not only as the most famous Finnish architect; but also as "the most significant representative of The Other Tradition of Modern Architecture who believed strongly in realism and humanism" (Pallasmaa 2019, p. 21). Alvar Aalto was a celebrity of his time, but as his name and fame are enduring, he can be regarded as a living brand (Lewis 2010) of the current time as well. The following citation is a concrete example of a living brand.

When a French group was here for the first time on a nature and fishing trip, there was an architect who was thrilled when he realized he was staying overnight in a 
house designed by Alvar Aalto. He no longer seemed to be that interested in fishing. I then took him to the design sauna (designed and decorated by architect Alvar Aalto in the 1940s). When we stepped in the architect, Bruno was his name, stood there without saying a word. He then went around touching the walls and tables and chairs. He starts tapping the phone and speaks French for a while, I don't know French. "We are coming here with a group of French architects next autumn." Last autumn he was here with a group of architects. You know, even though I appreciate this place very much, so this is something completely unique. (Interviewee 12, the executive director of the research center)

This study highlights the importance of the character of Alvar Aalto's work in branding a cultural route consisting of the Alvar Aalto cities. The significance of Alvar Aalto as an architect in the place branding emerged clearly in the values expressed. Alvar Aalto is considered a value in and of himself: his reputation is indisputable and established among architects worldwide, drawing foreign visitors from as far away as Japan. When interviewed, the cultural manager focused strongly on the architecture in attracting visitors and tourists to the village.

The findings of the study confirm that communicating joint goals, understanding the goals of all stakeholders, and fostering equal participation are important contributors to the process of joint value co-creation in branding a cultural route. The character of a cultural route contributes to establishing a common vision to guide the brand-building and especially the brand maintenance process. Important aspects of branding a cultural route are setting joint goals and encouraging equal degrees of participation among those involved. The value co-creation of an individual site must be in accordance with the cross-cultural significance of the route as a whole. This notion is very much linked to the content of the cultural route, in other words to the core and essence of the brand. This is a prerequisite for more integrated product development and for cohesive communication on the attraction of the sites along a cultural route.

\section{Conclusions}

The purpose of this study was to explore how a cultural route expresses the identity of the partner sites. The multistakeholder approach adopted in the study made it possible to explore the value co-creation in the context of branding a cultural route. The analysis was based on the theoretical discussion of place branding and cultural route. The current study contributes to the identity-based approach of placebranding theory (Kavaratzis and Hatch 2013) in highlighting how the image and the culture of a place interact and manifest in the context of a cultural route. The core character expressed through the place identity of a site inspired and prompted the expansion of a network of cities that ultimately formed a cultural route based on the significance of an architect's work. The study applies the paradigmatic shift from managerial to co-creative branding in the context of a cultural route and from consumer to multi-stakeholder approaches in marketing in line with the work of several researchers (Von Wallpach et al. 2017; Martinez 2016; Fan 2014). The study echoes the view of Kavaratzis and Hatch (2013) on the identity of a brand-here, a cultural routeemerging in a network of active partner sites that are equal regardless of the size of the site. Moreover, the study contributes to previous research on branding a cultural route in that it focuses on interaction and dialogue between stakeholders - as called for by Martinez (2016) and Fan (2014) without overlooking the significant role of local inhabitants in co-creating a cultural route as a brand.

Our study shows that integrated communication and marketing improves the visibility and accessibility of the sites. When that process of enhancing the visibility and accessibility has been completed, the sites can offer a service to tourists with a special interest in the built environment, architecture, and an architect's portfolio of work. This agrees with the idea that co-creation and communication are essential to the formation of a cultural route (Majdoub 2010). Following the arguments by Richards $(2007,2011)$ and Majdoub (2010) this study contributes to the research on cultural tourism focusing on how co-creation and collaboration between the sites of a cultural route enhance links between service providers and tourists, and thus increase contact with the local culture. The study also contributes to the academic branding discourse, in which cultural sites are at the core of the brand, by discussing the perspective of cultural sustainability (Auclair and Fairclough 2015). The increasing inclusion of tangible and intangible aspects of heritage in the tourism system is, however, prompting concerns about the sustainability of heritage (Richards 2018, 2020). The study follows the stream of research interested in the relationship between culture and place branding and which appreciates the role played by the culture of the place when residents and other stakeholders identify with a place's brand (Scaramanga 2015).

Furthermore, the current study contributes to placebranding theory by linking the discourse on architectural heritage and branding an emerging cultural route. Previous studies have focused more on the co-creation of a city's brand (e.g., Hatch and Schultz 2010; Merrilees et al. 2014; Casais and Monteiro 2019), whereas this study pays attention to a cultural route comprising Alvar Aalto sites. By linking the discourse on the architectural heritage attributable to a specific individual—architect Alvar 
Aalto-in branding an emerging cultural route, the study contributes to the theories of place branding and value cocreation. Earlier research on using architecture in branding has largely concentrated on branding individual cities (Muratowski, 2012; Cvitković and Kline 2017) even in the context of a cultural route (Mitoula and Kaldis, 2019), while this study focuses on using architecture in branding a cultural route to support a joint brand identity of several small localities. Muratowski (2012) argues that in several international cities, architecture has been used as a medium in branding that promotes social relationships and individual enterprises and can be used as a symbol of territorial identity. This study contributes to this because the Alvar Aalto cities exemplify the first case of such a symbol being applied to the branding of a cultural route.

This study offers a managerial implication in that it shows that the co-creative approach in branding a cultural route facilitates the sites collaborating, for example, in marketing their destinations and combining the offerings of several attractions that alone would struggle to attract visitors. For the local communities and the policymakers, cultural tourism and collaboration on a cultural route contribute to the sustainable development of the region. Finding sustainable strategies for cities of all sizes is a fundamental global challenge, but focusing on small and medium-sized cities-as this study does-illuminates the changing relationship between urban and rural realities (Soini and Dessein 2015). We have placed sustainable culture at the core of branding a cultural route connecting small towns and cities under a joint brand (Majdoub 2010). There is ample research on cities and sustainability, but unlike most of those contributions, our study highlights the value of a person (and that person's work as an architect) in branding a cultural route. The decision to extend a network of cities to constitute a cultural route around the core character of a variety of sites resonates strongly with how the residents of a local community perceive the identity of a place. Consequently, a cultural route is considered to have social and cultural value for the people who, for example, inhabit the buildings of its constituent sites and for the culture that they reflect. A cultural route can thus offer the prospect of enhanced wellbeing to the residents of its sites.

A limitation of the study is its very specific context and content and that it was conducted in one country. As an option for future studies, the theoretical framework of the study could be applied in contexts other than architectural ones and also in other countries. Moreover, surveying visitors to more than one place along the route and other relevant stakeholders in various countries and cultures would offer a more comprehensive picture of the phenomenon. A future study might also focus on the digitalization of a cultural route.
On behalf of all authors, the corresponding author states that there is no conflict of interest.

Funding Open access funding provided by University of Turku (UTU) including Turku University Central Hospital. Support and funding provided by the DISCE-project ( EU-H2020-822314).

Open Access This article is licensed under a Creative Commons Attribution 4.0 International License, which permits use, sharing, adaptation, distribution and reproduction in any medium or format, as long as you give appropriate credit to the original author(s) and the source, provide a link to the Creative Commons licence, and indicate if changes were made. The images or other third party material in this article are included in the article's Creative Commons licence, unless indicated otherwise in a credit line to the material. If material is not included in the article's Creative Commons licence and your intended use is not permitted by statutory regulation or exceeds the permitted use, you will need to obtain permission directly from the copyright holder. To view a copy of this licence, visit http://creativecommons.org/licenses/by/4.0/.

\section{References}

Aaker, D. 2014. Aaker on branding: 20 principles that drive success. New York: Morgan James Pub.

Aaker, D., and E. Joachimsthaler. 2000. Brand leadership. New York: The Free Press.

Alvar Aalto Cities. 2019. https://visit.alvaraalto.fi/en. Accessed 19 Sept 2019.

Alvar Aalto Foundation. 2019a. https://www.alvaraalto.fi/en/. Accessed 26 Sept 2019.

Alvar Aalto Foundation. 2019b. "Humanistic Modernism" - works by Alvar Aalto in the World Heritage Context." Seminar material 9-10 October 2019. Lahti, Finland.

Arezki, R., R. Cherif, and J. Piotrowski. 2009. Tourism specialization and economic development: Evidence from the UNESCO World Heritage list. Washington DC: International Monetary Fund.

Ashworth, G. 2010. Personality association as an instrument of place branding: Possibilities and pitfalls. In Towards effective place brand management, ed. G. Ashworth and M. Kavaratzis, 222-233. Cheltenham: Edward Elgar.

Auclair, E., and G. Fairclough. 2015. Living between past and present: An introduction to heritage and cultural sustainability. In Theory and practise in heritage and sustainability. Between past and future, ed. E. Auclair and G. Fairclough, 1-22. London: Routledge.

Authors. 2021. For anonymity reasons no further information is given about the publication.

Bell, E., A. Bryman, and B. Harley. 2019. Business research methods. Oxford, UK: Oxford University Press.

Braun, V., and V. Clarke. 2006. Using thematic analysis in psychology. Qualitative Research in Psychology 3: 77-101.

Braun, E., M. Kavaratzis, and S. Zenker. 2013. My city-my brand: The different roles of residents in place branding. Journal of Place Management and Development 6 (1): 18-28.

Casais, B., and P. Monteiro. 2019. Residents' involvement in city brand co-creation and their perceptions of city brand identity: a case study in Porto. Place Branding and Public Diplomacy 15 (4): 229-237. 
Cvitkovic, S., and M. Kline. 2017. Skopje. Rebranding the Capital City through Architecture and Monuments to Remake the Nation Brand. Sociologija i prostor, 55 (1): 33-53. https://doi. org/10.5673/sip.55.1.2.

Del Barrio, M.J., M. Devesa, and L.C. Herrero. 2012. Evaluating intangible cultural heritage: The case of cultural festivals. City, Culture and Society 3 (4): 235-244.

Della Lucia, M., and M. Trunfio. 2018. The role of the private actor in cultural regeneration: Hybridizing cultural heritage with creativity in the city. Cities 82 : 35-44.

Dovey, K. 2014. Framing places: Mediating power in built form. London: Routledge.

Frey, B.S., P. Pamini, and L. Steiner. 2011. What determines the World Heritage list? An econometric analysis. An Econometric Analysis (January 1, 2011). University of Zurich Department of Economics Working Paper (1).

Evans, G. 2015. Rethinking place branding and place making through creative and cultural quarters. In Rethinking place branding, ed. M. Kavaratzis, G. Warnaby, and G.J. Ashworth, 135-158. Vienna: Springer.

Fan, H. 2014. Branding a place through its historical and cultural heritage: The branding project of Tofu Village in China. Place Branding and Public Diplomacy 10 (4): 279-287.

Hatch, M.J., and M. Schultz. 2010. Toward a theory of brand co-creation with implications for brand governance. Journal of Brand Management 17 (8): 590-604.

Holma, M., and M. Lahti. 1996. Alvar Aalto. Elämälle herkempi rakenne. Helsinki: Rakennustieto Oy.

Jimura, T. 2011. The impact of world heritage site designation on local communities-A case study of Ogimachi, Shirakawa-mura, Japan. Tourism Management 32 (2): 288-296.

Kavaratzis, M., and M.J. Hatch. 2013. The dynamics of place brands: An identity-based approach to place branding theory. Marketing Theory 13 (1): 69-86.

Kayahan, B., and B. Vanblarcom. 2012. Cost benefit analysis of UNESCO World Heritage site designation in Nova Scotia. Review of Economic Analysis 4 (2): 247-273.

Neuendorf, K., P. Skalski, J. Cajigas, and J. Allen. 2017. The content analysis guidebook. Los Angeles: SAGE.

King, L.M. 2011. Investigating the role of the World Heritage brand in attracting visitors to protected areas in Queensland, Australia. $\mathrm{PhD}$ thesis. James Cook University.

King, L.M., and E.A. Halpenny. 2014. Communicating the World Heritage brand: Visitor awareness of UNESCO's World Heritage symbol and the implications for sites, stakeholders and sustainable management. Journal of Sustainable Tourism 22: 1-19.

Knights, D., and D. McCabe. 1997. How could you measure something like that? Quality in a Retail Bank. Journal of Management Studies 34 (3): 371-388.

Lewis, T. 2010. Branding, celebritization and the lifestyle expert. $\mathrm{Cul}$ tural Studies 24 (4): 580-598.

Lury, C. 2004. Brands: The logos of the Global Economy. New York: Routledge.

Majdoub, W. 2010. Analyzing cultural routes from a multidimensional perspective. Almatourism-Journal of Tourism, Culture and Territorial Development 1 (2): 29-37.

Martínez, N.M. 2016. Towards a network place branding through multiple stakeholders and based on cultural identities. Journal of Place Management and Development. 9 (1): 73-90.

Mayes, R. 2008. A place in the sun: The politics of place, identity and branding. Place Branding and Public Diplomacy 4 (2): 124-135.

Merriam, S.B., and E.J. Tisdell. 2016. Qualitative research. A guide to design and implementation. San Francisco: Jossey-Bass.

Merrilees, B., D. Miller, W.D. Shao, and C. Herington. 2014. Linking city branding to social inclusiveness: A socioeconomic perspective. Place Branding and Public Diplomacy 10: 267-278.
Mitoula, R., and P. Kaldis. 2019. City branding and cultural routes. Sustainable Development, Culture, Traditions Journal. Special Volume in Honor of Professor George I. Theodoropoulos. https:// doi.org/10.26341/issn.2241-4002-2019-sv-12.

Moilanen, T., and S. Rainisto. 2009. How to brand nations, cities and destinations: A planning book for place branding. Basingstoke: Palgrave Macmillan.

Muratowski, G. 2012. The Role of Architecture and integrated design in city branding. Place Branding and Public Diplomacy 8 (3): 195-207.

Pallasmaa, J. 2019. Alvar Aalto's Humanistic World-Towards a synthetic architecture. In Alvar Aalto Foundation 2019b. "Humanistic Modernism"-Works by Alvar Aalto in the World Heritage Context", 19-31. Seminar material 9-10 October2019, Lahti, Finland.

Parkerson, B., and J. Saunders. 2005. City branding: Can goods and services branding models be used to brand cities? Place Branding and Public Diplomacy 1: 242-264.

Patton, M.Q. 2002. Qualitative research \& evaluation methods, 3rd ed. Thousand Oaks (CA): Sage Publications Ltd.

Pedeliento, G., and M. Kavaratzis. 2019. Bridging the gap between culture, identity and image: A structurationist conceptualization of place brands and place branding. Journal of Product \& Brand Management 28 (3): 348-363.

Rapley, T., and G. Rees. 2018. Collecting documents as data. In The SAGE handbook of qualitative data collection, ed. U. Fick, 378391. London: SAGE.

Richards, G. 2007. Cultural tourism, global and local perspectives. New York: Routledge.

Richards, G. 2011. Cultural tourism trends in Europe: A context for the development of Cultural Routes. In Impact of European Cultural Routes on SMEs' innovation and competitiveness, ed. K. Khovanova-Rubicondo, 21-39. Strasbourg: Council of Europe Publishing.

Richards, G. 2018. Cultural tourism: A review of recent research and trends. Journal of Hospitality and Tourism Management 36: $12-21$.

Richards, G. 2020. Designing creative places: The role of creative tourism. Annals of Tourism Research, 85.

Riessman, C. 2004. Narrative interviewing. In Encyclopedia of social science research methods, ed. M.S. Lewis-Beck, A. Bryman, and L.T. Futing, 705-709. London: Sage.

Ryan, G.W., and H.R. Bernard. 2003. Techniques to identify themes. Field Methods 15: 85-109.

Scaramanga, M. 2015. Place branding and culture: The reciprocal relationship between culture and place branding. In Harnessing place branding through cultural entrepreneurship, ed. F. Go, A. Lemmetyinen, and U. Hakala, 31-47. New York: Palgrave McMillan.

Silverman, D. 2013. Doing qualitative research, 3rd ed. London: Sage Publications.

Soini, K., and J. Dessein. 2015. Series introduction. In Theory and practise in heritage and sustainability. Between past and future, ed. E. Auclair and G. Fairclough, xvi-xvii. London: Routledge, London.

Stake, R.E. 1995. The art of case study research. Thousand Oaks, CA: Sage.

Tedlock, B. 2000. Ethnography and ethnographic representation. In Handbook of qualitative research, ed. N.K. Denzin and Y.S. Lincoln, 455-488. Thousand Oaks: Sage Publications.

Vargo, S.L., and R.F. Lusch. 2008. Service-dominant logic: Continuing the evolution. Journal of the Academy of Marketing Science 36 (1): $1-10$.

Warnaby, G. 2009. Towards a service-dominant place marketing logic. Marketing Theory 9: 403-423. 
Von Wallpach, S., B. Vover, M. Kastanakis, and H. Mühlbacher. 2017. Co-creating stakeholder and brand identities: Introduction to the special section. Journal of Business Research 70: 395-398.

Wuepper, W., and M. Patry. 2017. The World Heritage list: Which sites promote the brand? A big data spatial econometrics approach. Journal of Cultural Economics 41 (1): 1-21.

Yin, R.K. 2003. Case study research: Design and methods, 3rd ed. Thousand Oaks, CA: Sage.

Publisher's Note Springer Nature remains neutral with regard to jurisdictional claims in published maps and institutional affiliations.

Arja Lemmetyinen D.Sc. (Econ. \& Bus. Adm.) is an Adjunct Professor (Åbo Akademi University) and currently working as a University Researcher (marketing) at the University of Turku, Turku School of Economics, Pori Unit, Finland. Her research interest lies firstly in brand management and place branding. She is also interested in research on network management and value co-creation in networks. Lately her research interest has focused on sustainability in its economic, social, environmental and cultural significance and also in digital brand experiences.

Lenita Nieminen M.Sc. (Econ. \& Bus.Adm.) is currently working as a Project Researcher (Entrepreneurship) at the University of Turku, Turku School of Economics, Pori Unit, Finland. She has a twenty-year background in creative economies. Her research focuses on entrepreneurial learning and the role of entrepreneurial networks in micro business development, and she has been engaged as a reseracher in several regional and international entrepreneurship projects, specialising in cultural tourism.

Johanna Aalto. LL.D. Development Manager at the Laurea University of Applied Sciences, Finland. Main areas of research and teaching include brands, jurisdiction, public management, participation and local development. Most recent the focus has been in developing legal value visibility, legal design and co-creation, how to get legal contents more intelligible. 